\title{
Nutrition transition in Chile: determinants and consequences
}

\author{
Cecilia Albala*, Fernando Vio, Juliana Kain and Ricardo Uauy \\ Institute of Nutrition and Food Technology (INTA), University of Chile, Casilla 138-1 1, Av. Macul 5540, Santiago, \\ Chile
}

\begin{abstract}
Objectives: The purpose of this study was to analyse the determinants and consequences of the nutrition transition in Chile and describe the related health promotion policies.

Design and setting: This is a descriptive, population-based study including data on demographic, diet, nutrition and biomedical related variables. Data came from the Food and Agriculture Organization (FAO), the National Institute of Statistics (INE), the Ministries of Planning, Health and Education surveillance systems, and national surveys.

Results: As malnutrition decreased during the 1980s, obesity increased rapidly in all age groups. In adults, currently about $25 \%$ of women are obese (body mass index $>30 \mathrm{~kg} \mathrm{~m}^{-2}$ ); particularly those from low socio-economic levels. Among preschoolers, obesity is now 10\% while in 6-year-old children it is $17.5 \%$ (weight/height greater than two standard deviations (>2SD) of the World Health Organization reference). Nutritional risk factors are prevalent, diet is changing to a 'Western diet' with an increasing fat consumption, and sedentarianism is constant in all groups. High blood pressure $(>140 / 90)$ is greater than $10 \%$ in adults. Diabetes is increasing in urban areas, including in the indigenous population, and more than $40 \%$ of adults have a cholesterol level of more than $200 \mathrm{mg} \mathrm{ml}^{-1}$.

Conclusions: Promotion of healthy lifestyles is the main strategy to cope with this situation, particularly changing behaviour in food habits, physical activity and psychosocial factors. Changes in lifestyles will not only allow the prolonged life expectancy to be of better quality, but also will favour a decrease in the morbidity and mortality from chronic diseases, mainly cardiovascular diseases.
\end{abstract}

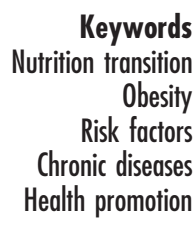

The unique characteristic of the epidemiological transition in Chile has been its rapid progression. In 1971, Omran classified the country as a "contemporary or delayed model $^{1}$; however, by the 1990s, it had changed to an 'accelerated model' similar to Japan. Chile was in the transition period in the 1970 s but progressed to a posttransition stage by the end of the 1980s. Now, at the beginning of the 21st century, Chile has a life expectancy at birth (LEB) of 80 years for women and 73 years for men, and is facing a fourth phase of the process: the advanced mortality profile ${ }^{2}$, characterised by the delay of deaths caused by degenerative diseases ${ }^{3}$.

The main mechanisms involved in the Chilean epidemiological transition are the increase of risk factors for chronic diseases (characteristic of the urbanisation process) that has affected the incidence of chronic diseases, the fertility decline (which has changed the age structure of the population), and the improvement in casefatality rates. Chile underwent rapid modernisation in the decade of the 1990s as a consequence of economic growth. This economic growth produced positive effects in relation to coverage of potable water and sanitation; decreases in infectious diseases, malnutrition and infant mortality rates; and increases in the access to education, health and other community services ${ }^{4-6}$. On the other hand, this growth produced negative effects on lifestyle, such as the turning to a 'Western diet' and its predominance of fast food consumption ${ }^{7}$, and a decrease in physical activity. Additionally, an increase in alcohol and drug abuse and a sustained, high prevalence of smoking habit have been observed; air pollution has also increased considerably, particularly in big cities like Santiago, one of the most polluted cities in Latin America ${ }^{8}$.

Chile is simultaneously experiencing the demographic and epidemiological transitions, resulting in an ageing population and a shift from infectious to chronic diseases. The nutrition transition experience in Chile is related to demographic and socio-economic changes ${ }^{4-6,9,10}$, dietary changes, obesity and sedentary lifestyles, which in turn have affected blood cholesterol, diabetes and hypertension. This paper examines the determinants and consequences of the nutrition transition in Chile and their relationship with its health promotion policies.

\section{Mortality changes}

With respect to general mortality, the proportion of cardiovascular disease has had a sustained increase from 
1970 (22.3\% of total deaths) to 1992 (29\%) and a posterior stabilisation $^{11}$. This proportion is higher than the average observed in the developing world (19\% of all deaths) ${ }^{12,13}$, also higher than the rate in Canada $(22 \%)^{14}$. The proportion of deaths from malignant tumours also increased, from $12 \%$ to $21.6 \%$, in the same period. At the same time, a reduction has been observed in injuries, and infectious and perinatal diseases (Fig. 1). Respiratory diseases have decreased in childhood, but in the general epidemiological profile of the country they are again a leading cause of mortality, mainly due to the mortality from these in persons aged 75 years and above.

According to the 1998 World Health Report ${ }^{15}$, the global burden of non-communicable diseases corresponds to $43 \%$ of all Disability-Adjusted Life Years (DALYs) lost. Cardiovascular diseases alone are responsible for 10\% of lost DALYs in low-income countries whereas, in industrialised countries, the proportion increases to $23 \%$. A disease burden study conducted in Chile in 1995, with mortality data from 1993, revealed that chronic diseases are the main cause of DALYs lost, accounting for $73 \%$ of the total ${ }^{16}$. Of this total, cardiovascular diseases were the highest cause of DALYs lost, accounting for 10.3\%. Life years lost by premature death in the same years (1993-94) were mainly due to injuries (26.2\%), followed by tumours (17.8\%) and cardiovascular diseases (13.6\%) .

\section{Dietary changes}

The nutrition transition brings significant dietary changes; increases in total fat, mostly saturated fat, is the most prominent. As income increases in transitional countries, so does the consumption of fat, including industrially processed hydrogenated $\mathrm{fat}^{7}$. The combination of the diet change and sedentary lifestyle is perfect to trigger increasing adiposity. Recent data from several urban centres, including data obtained in Santiago, demonstrate that TV viewing and a child's preference for certain TV commercials has a direct relationship with snack food consumption and other food purchased by children at school $^{17}$. The progressive rise in overweight and obesity is especially prevalent in low-income groups who improve their income and subsequently buy high-fat/high-carbohydrate energy-dense foods. There is a marked consumer preference in the urban supermarket for sweet and salty, high-fat foods; intake of these increases to the detriment of grains, fruits and vegetables. Dietary factors are associated with the main causes of death: cardiovascular diseases and cancer. Dietary patterns have changed rapidly in Chile to the so-called 'Western diet', rich in saturated fat, as described in a previous paper ${ }^{6}$. Analysis of the Food and Agriculture Organization's (FAO) Food Balance Sheets demonstrates that the availability of total calories and calories from fat have increased in the last two decades, with a major increase in saturated fats (Fig. 2). In fact, in 1980, the average per capita availability for calories and fat was $2667 \mathrm{kcal}$ (21\% from fat), increasing to $2844 \mathrm{kcal}$ (28\% from fat) in $1998^{18}$.

Existing data from studies done between 1960 and 1989 estimating food intake in Chile $^{8}$ show that the average caloric contribution of macronutrients in the Chilean diet consisted of $10-13 \%$ protein, $20-25 \%$ fat and $60-70 \%$ carbohydrates, without any relevant changes in the period. A recent comparative analysis of the National Household Surveys on Food Expenditure conducted in 1988 and $1998^{19}$ has demonstrated that the main expenditure of the poor is for bread, meat and soft drinks, meaning that the preferences of the poor are in the first place for the staple food in Chile (bread) and then for food with a high proportion of saturated fat (meat) and sugar (soft drinks). Converted into energy and macronutrients, an increase of 22\% in average total calories and an increase in average fat consumption of $26 \%$ are observed (Table 1 ). Additionally, a cross-sectional survey on food consumption, conducted in Santiago in $1995^{20}$, demonstrated that $70 \%$ of adults consumed less than two fruits and 59\% consumed less than two portions of vegetables per day.

\section{Sedentary lifestyle}

Sedentary behaviour is one of the main contributory factors to increasing obesity rates. The explanation for this increase has been attributed to inactivity, especially from spending more hours per week watching TV and the utilisation of more vehicles and activity-saving appliances $^{21}$. In Chile, the number of cars by 1000 inhabitants was 38.9 in 1970, increasing to 136.6 in 1998, and TV appliances increased from 12170 in 1970 to more than two million in $1998^{22}$. A survey carried out in 1998 on a representative sample of school children in Santiago showed that at least 90\% watch an average of 2 hours of TV on weekdays ${ }^{17}$. Two surveys on risk factors for chronic diseases, conducted in the Santiago population over 15 years of age in 1988 and $1992^{23,24}$, indicated that about $60 \%$ of men and $80 \%$ of women performed less than two 15-minute periods of exercise per week. In another study conducted in 1997 on a representative sample (25-64 years of age) in urban Valparaiso, Chile ${ }^{25}$, 93\% of women in 1997 were inactive in their leisure time; this was even higher (97\%) in the low socio-economic group. The CASEN survey 2000, conducted in a national representative sample ${ }^{10}$, demonstrated that only $8.6 \%$ of the population $>15$ years performed more than 30 minutes of exercise three times per week and $71 \%$ did not performed any type of exercise. All of these data demonstrate the high level of sedentarianism in the Chilean population.

\section{Obesity}

Trends demonstrate a progressive rise of obesity rates. Chile has evolved over the past two decades, from high 


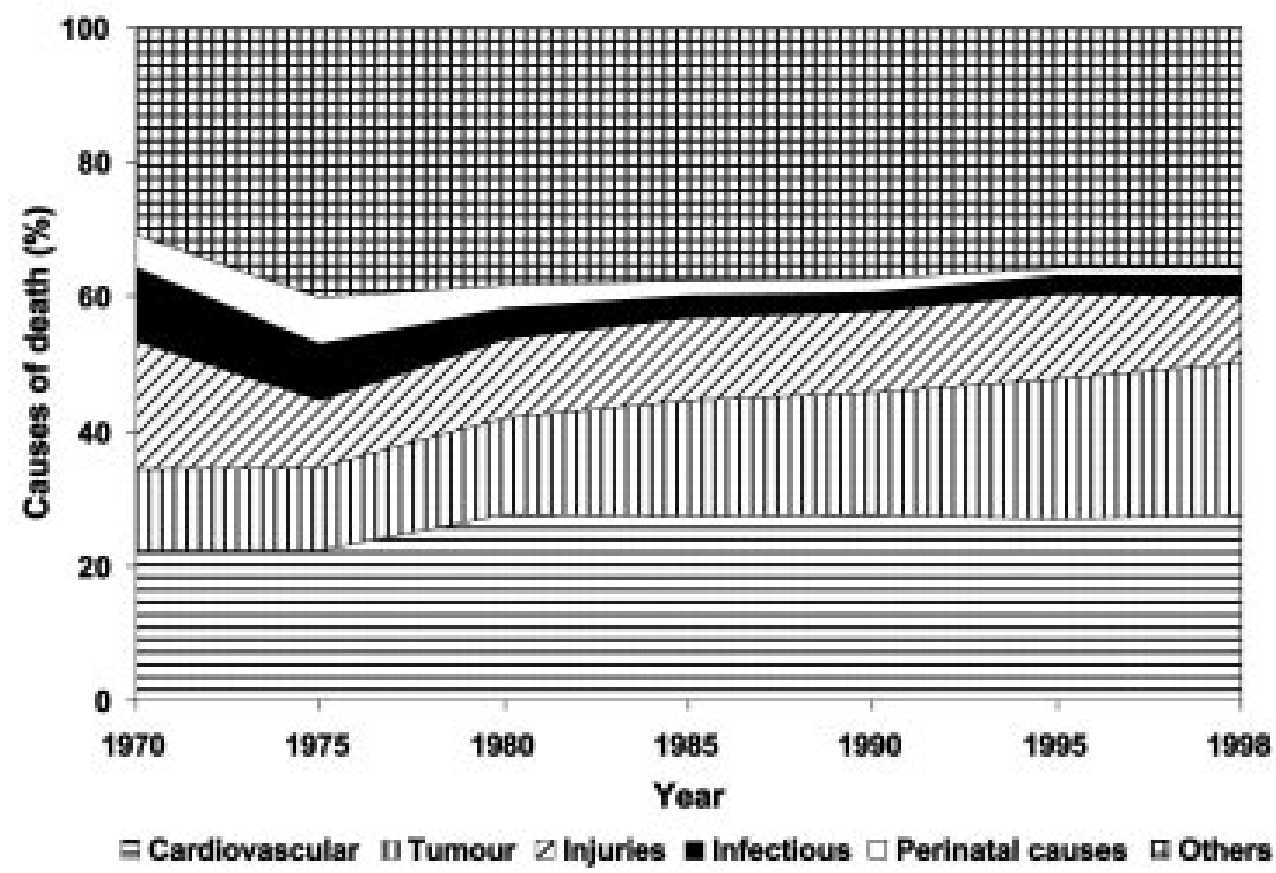

Fig. 1 Trends in relative contribution to causes of death, Chile 1970-1998

undernutrition and low obesity rates, to the virtual eradication of undernutrition and high obesity prevalence in all age groups. Concomitantly, a decrease in the rate of stunting has been observed as well as a decline in the prevalence of birth weight under $2500 \mathrm{~g}$, currently about $5 \%$ of all births ${ }^{26}$.

Obesity prevalence has doubled in pre-school and school-aged children over the past decade ${ }^{27}$ as shown in Fig. 3. The situation of pregnant women has also changed dramatically, with a decrease in undernourished mothers from $26 \%$ in 1987 to $14.1 \%$ in 2000 , while obesity has increased from $12.9 \%$ to $32.7 \%$ in the same period ${ }^{26}$. In two surveys conducted in 1988 and 1992 among adults in
Santiago, obesity increased from $6 \%$ to $11 \%$ and from $14 \%$ to $24 \%$ in men and women respectively, over a four-year period. Obesity increased with age, was more prevalent in women than in men, and was higher in women of low socio-economic level ${ }^{23,24}$. In Valparaiso, the second largest city, obesity prevalence was also high and had a similar distribution to that found in Santiago ${ }^{25}$. Changes in the diet and sedentarianism are the most probable causes of the increasing trend of obesity in Chile.

\section{Blood cholesterol}

Studies indicate that serum cholesterol is affected by diet

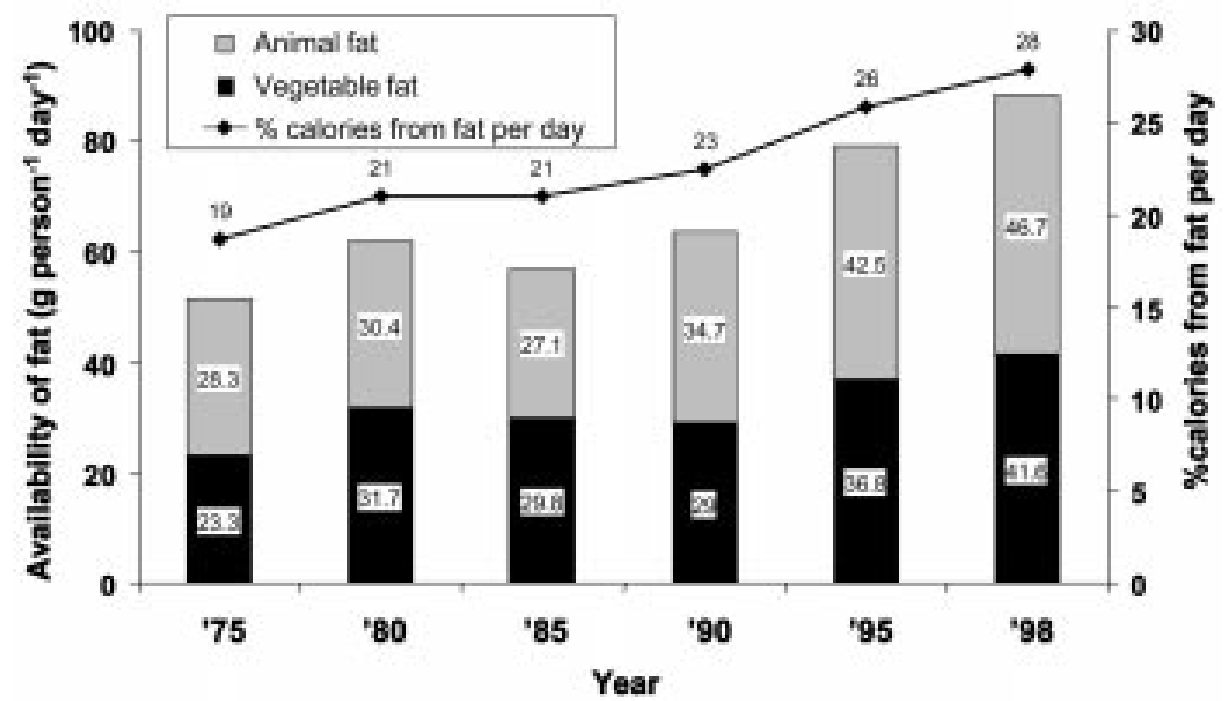

Fig. 2 Availability of fat per capita, Chile 1975-1998 
Table 1 Food expenditure and food converted into macronutrients by income quintile and year

\begin{tabular}{|c|c|c|c|c|c|c|c|c|c|c|}
\hline & \multicolumn{10}{|c|}{ Income quintile and year } \\
\hline & \multicolumn{2}{|c|}{ I (lowest) } & \multicolumn{2}{|c|}{ II } & \multicolumn{2}{|c|}{ III } & \multicolumn{2}{|c|}{ IV } & \multicolumn{2}{|c|}{ V (highest) } \\
\hline & 1988 & 1998 & 1988 & 1998 & 1988 & 1998 & 1988 & 1998 & 1988 & 1998 \\
\hline \multicolumn{11}{|c|}{ Food (\% of total expenditure) } \\
\hline Meat & 9.4 & 9.4 & 9.7 & 10.0 & 10.2 & 9.9 & 11.2 & 9.4 & 11.9 & 7.9 \\
\hline Soft drinks & 2.2 & 7.3 & 3.1 & 9.3 & 3.3 & 8.1 & 3.4 & 7.5 & 3.0 & 5.2 \\
\hline Bread & 21.2 & 15.0 & 18.6 & 12.2 & 15.1 & 10.4 & 11.9 & 8.1 & 5.9 & 4.4 \\
\hline Chicken & 5.5 & 5.6 & 5.5 & 5.0 & 5.3 & 4.7 & 5.2 & 4.0 & 3.9 & 2.9 \\
\hline Sausage & 2.9 & 3.8 & 3.2 & 3.7 & 3.2 & 3.7 & 3.2 & 3.3 & 3.3 & 2.8 \\
\hline Away from home & 1.9 & 2.7 & 2.6 & 4.3 & 4.9 & 6.0 & 5.8 & 9.9 & 12.8 & 19.1 \\
\hline All others & 56.9 & 56.2 & 57.3 & 44.5 & 58.0 & 57.2 & 59.3 & 57.8 & 59.2 & 57.7 \\
\hline Total & 100 & 100 & 100 & 100 & 100 & 100 & 100 & 100 & 100 & 100 \\
\hline \multicolumn{11}{|c|}{ Total food expenditure converted into calories and macronutrients (daily consumption) } \\
\hline Energy (cal) & 1640 & 2010 & 1617 & 2070 & 1734 & 2129 & 1988 & 2269 & 2200 & 2492 \\
\hline Carbohydrates (g) & 231 & 271 & 230 & 287 & 244 & 302 & 277 & 327 & 292 & 349 \\
\hline Protein (g) & 44.5 & 55.7 & 43.3 & 59.3 & 47.4 & 59.8 & 55.5 & 64.1 & 65.0 & 74.0 \\
\hline Fat (g) & 42.2 & 55.4 & 42.3 & 61.2 & 47.5 & 63.6 & 57.3 & 68.4 & 72.1 & 80.1 \\
\hline$\%$ of energy from fat & 23.2 & 24.8 & 23.5 & 26.6 & 24.7 & 26.9 & 25.9 & 27.1 & 29.5 & 28.9 \\
\hline
\end{tabular}

Source: INE National Household Surveys on Food Expenditure, 1988 and $1998^{19}$.

quality and quantity. In Chile a 1984 survey of outpatients from two large hospitals in Santiago ${ }^{28}$, which served a lowincome population, found a median serum cholesterol level of $185 \mathrm{mg} \mathrm{dl}^{-1}$. At the same time, significantly lower levels of cholesterol were found in women of low socioeconomic level (SEL) than in women of high $\mathrm{SEL}^{29}$. In 1987 , a survey carried out in Santiago ${ }^{23}$ found a prevalence of cholesterol greater than $200 \mathrm{mg} \mathrm{dl}^{-1}$ in $32 \%$ of men and $33 \%$ of women, increasing with age and income. In 1992, the proportion increased to over $40 \%$ in both men and women ${ }^{24}$; in Valparaiso in $1997^{25}$, the values were $45.2 \%$ for men and $48 \%$ for women. The prevalence of cholesterol greater than $200 \mathrm{mg} \mathrm{dl}^{-1}$ is more than $10 \%$ among children and adolescents ${ }^{30,31}$.

\section{Type 2 diabetes}

The link between obesity and type 2 diabetes is one of the most powerful risk factor-disease relationships known ${ }^{32}$. As a consequence, diabetes rates are escalating rapidly and have an earlier onset, leading to major health problems and financial burden ${ }^{33}$.

The prevalence of type 2 diabetes was $5.3 \%$ in a representative Santiago sample in $1979^{34}$ and $4 \%$ in Valparaiso in $1997^{25}$. Our studies over the past five years have examined the effects of the environment on the prevalence of obesity, glucose intolerance and diabetes in the indigenous population. In rural areas, where Mapuche (indigenous people of Chile) ethnical and cultural

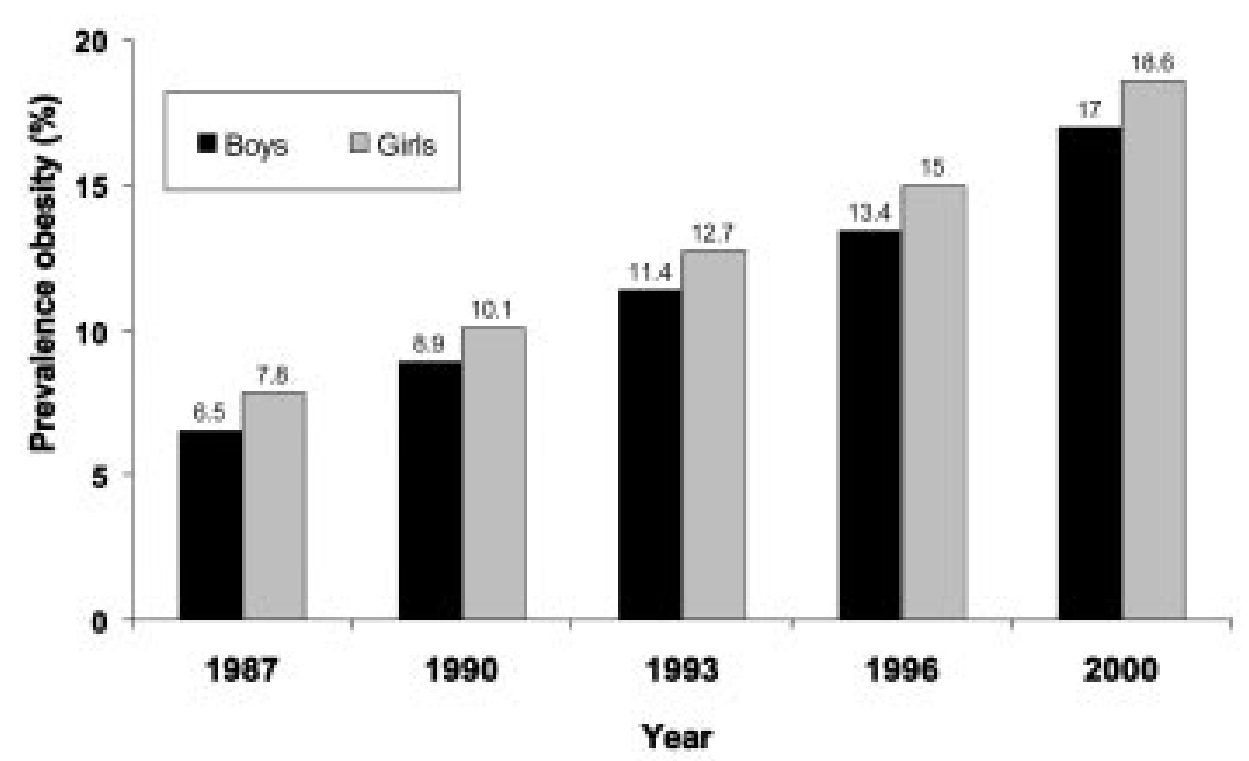

Fig. 3 Prevalence of obesity in first-grade school children, Chile $1986-2000^{27}$. Obesity is defined as weight/height greater than two standard deviations ( $>$ 2SD) of the National Center for Health Statistics (NCHS)/World Health Organization (WHO) reference 
Table 2 Prevalence of high blood pressure in the adult population of Chile (19781998)

\begin{tabular}{lllr}
\hline Author and year & \multicolumn{1}{c}{ Location } & Classification & $\begin{array}{r}\text { Prevalence } \\
(\%)\end{array}$ \\
\hline Rodríguez and Dockendorf, 1978 & Rural IX Region & $>160 / 95$ & 18.4 \\
Berríos et al., $1987^{23}$ & Santiago & $>160 / 95$ & 8.8 \\
Fasce et al., $1989^{39}$ & Urban VIII Region & $>140 / 90$ & 18.6 \\
Fasce et al., $1991^{40}$ & Rural VIII Region & $>140 / 90$ & 22.8 \\
Vega et al., $1998^{38}$ & Urban Valparaiso & $>140 / 90$ & 11.1 \\
\hline
\end{tabular}

distinctive characteristics are preserved, the prevalence of diabetes was $0.98 \%$ in $1985^{35}$; one of the lowest ever found. In 1995-1996, Mapuche of rural areas were compared with Caucasian subjects from the general population of Santiago and Mapuche living in Santiago $^{36,37}$. The study revealed a higher prevalence of obesity and diabetes in urban Mapuche compared with rural natives. We found $4.1 \%$ of diabetics in rural Mapuche, compared with $9.8 \%$ in urban Mapuche and $5.3 \%$ in the Caucasian population of Santiago. Glucose intolerance was identified in $3.4 \%$ of the rural Mapuche and in $6.1 \%$ of the urban Mapuche.

\section{Hypertension}

A high salt consumption and obesity have long been recognised as some of the strongest independent risk factors for the development of hypertension.

Several local studies carried out from 1978 to $1998^{23-}$ 25,38-41 have examined the prevalence of hypertension in the country, as shown in Table 2. There is a high proportion of hypertensive people ( $11.1 \%$ to $22.8 \%$ ), which is higher in rural than in urban areas. In the last risk factors study conducted in a representative urban sample, aged 25-64 years, in 1997 in Valparaiso ${ }^{25}$, the adjusted prevalence of hypertension was $11.1 \%$, increasing with age, reaching $27.4 \%$ in the $55-64$-year-old group. In the same study, $16.5 \%$ of those interviewed added salt to their meals before determining the need ${ }^{42}$. All studies have shown that at least a third of the people with the disease do not know of their condition, and among those diagnosed, at least a third are not controlled. Hypertension also constitutes the main cause for medical attention at the primary level in the public sector and $9.3 \%$ of the total consultations ${ }^{16}$.

\section{Conclusions}

Chile is undergoing a rapid nutritional transition with a progressive increase in risk factors for non-communicable chronic diseases. The contributions of rising income, increased urbanisation, increase in apparent fat consumption and sedentary behaviour can probably explain this rise. All of these factors determined changes in lifestyle, especially diet and physical activity, which are similar to those observed in industrialised societies; the unique characteristic in Chile is that the rate of change has been faster. In fact, Chile changed rapidly from a pre-transition to a post-transition situation (with an adequate preventive maternal and child policy, which decreased infant mortality and maternal mortality rates) in two decades. The same capacity that proved so effective in improving all of the biomedical indices related to poverty, can serve to attack the increasing prevalence in risk factors for chronic diseases through a health promotion policy ${ }^{5}$. In the past, Chile was able to decrease malnutrition in a relatively short period of time with the implementation of adequate policies. Presently, the challenge is different and more difficult; it requires an integrated effort to change the behaviour of the population regarding food, physical activity, tobacco consumption, stress, etc. This is not compatible with the principles of economic development and advertisement, which aim at increasing the intake of fast food and soft drinks, at using cars and electric appliances more frequently with minimal physical activity, and at increased consumption of tobacco and other addictive substances.

The health promotion policy focuses on food, nutrition, physical activity, tobacco, psychosocial factors and environment. These are addressed in an integrated way in the pre-school and school systems, at workplaces, and at the county and small community level. The government is committed to support these policies with funding and regulations ${ }^{43}$. If these health promotion policies succeed in producing positive changes in lifestyles, the quality of life over the prolonged life expectancy will be better and there will be a decrease in morbidity and mortality for chronic diseases, especially cardiovascular diseases.

\section{References}

1 Omran AR. The epidemiologic transition: a theory of the epidemiology of population change. Milbank Q. 1971; 49: 509-38.

2 Frenk J, Bobadilla JL, Lozano R. The epidemiologic transition: the Latin American experience. Seminar on Causes and Prevention of Adult Mortality in Developing Countries, Santiago, Chile. International Union for the Scientific Study of Population (IUSSP), 1991.

3 Olhansky SJ, Ault AB. The fourth stage of the epidemiologic transition: the age of delayed degenerative diseases. Milbank Q. 1986; 64: 355-90.

4 Albala C, Vio F. Epidemiological transition in Latin America: the case of Chile. Public Health 1995; 109: 431-42. 
5 Vio F, Albala C, Crovetto M. Health promotion in the Chilean epidemiological transition. Rev. Chil. Nutr. 2000; 27: 21-9.

6 Vio F, Albala C. Nutrition policy in the Chilean transition. Public Health Nutr. 2000; 3: 49-55.

7 Popkin BM. Nutritional patterns and transition. Popul. Dev. Rev. 1993; 19: 138-57.

8 The World Bank. The Risk Factors In Chile. The Adult Health Policy Challenge. Washington, DC: The World Bank, 1995; 51.

9 Ministry of Health. Performance Report. Health Situation in Chile 1999. Santiago: Department of Communications and Public Relations, 2000.

10 Ministry of Planning (MIDEPLAN). CASEN Survey Reports 1998 and 2000. Santiago: Ministry of Planning, 1999 and 2001.

11 National Institute of Statistics (INE). Demographic Annual Reports 1970, 1975, 1980, 1985, 1990, 1995 and 1998. Chile: INE, 1970/1975/1980/1985/1990/1995/1998.

12 World Health Organization (WHO). The state of the world health. World Health Forum: Int. J. Health Dev. 1995; 16: $377-85$.

13 Murray CJ, Lopez AD. Mortality by cause for eight regions of the world: Global Burden of Disease Study. Lancet 1997; 349: 1269-76.

14 Heart and Stroke Foundation of Canada (HSFC). Causes of Death in Canada. Ottawa: HSFC, 1993 (Supplement).

15 World Health Organization (WHO). The World Health Report 1998. Life in the 21st Century. A Vision for All. Geneva: WHO, 1998.

16 Ministry of Health, Department of Epidemiology. Health Situation. Santiago: Ministry of Health, 1996.

17 Olivares S, Albala C, Garcia F, Jofre I. Television publicity and food preferences of school age children of the Metropolitan Region. Rev. Med. Chile 1999; 127: 791-9.

18 Food and Agriculture Organization (FAO). FAO Food Balance Sheets 1988 and 1998 [Online]. Available at http://www.fao.org. [Accessed September 2000].

19 National Institute of Statistics (INE). National Housebold Surveys on Food Expenditure 1988 and 1998. Chile: INE, 1988 and 1998.

20 Atalah E, Urteaga C, Rebolledo A. Food consumption of natural antioxidants in adults' diet. Rev. Chil. Nutr. 1995; 23: 34-41.

21 Prentice AM, Jebb SA. Obesity in Britain: gluttony or sloth? Br. Med. J. 1995; 311: 437-9.

22 National Institute of Statistics (INE). Statistic Summary 2000. Chile: INE, 2000.

23 Berríos X, Jadue L, Zenteno J, Ross MI, Rodriguez H. Prevalence of risk factors for chronic diseases: a population study in the Metropolitan Area of Santiago, Chile. 19861987. Rev. Med. Chile 1990; 118: 597-604.

24 Berrios X. Risk factors in adult chronic diseases. An example of epidemiologic research. Boletin Esc. Medicina P. Universidad Católica de Chile 1994; 23: 73-89.

25 Jadue L, Vega J, Escobar MC, Delgado I, Garrido C, Lastra P, Espejo F, Peruga A. Risk factors for chronic non communicable diseases: methods and results of CARMEN program basal survey. Rev. Med. Chile 1999; 127: $1004-13$
26 Albala C, Vio F, Kain J, Uauy R. Nutrition transition in Latin America: the case of Chile. Nutr. Rev. 2001; 59: 170-6.

27 Kain J, Uauy R, Vio F, Albala C. Trends in overwight and obesity prevalence in Chilean children: comparison of three definitions. Eur. J. Clin. Nutr. 2002 [in press].

28 Gomez R, Sandoval S, Getavagno A. Reference values for the adult population in clinical chemistry. Boletín del Instituto de Salud Pública de Chile 1984; 25: 236-40.

29 Albala C, Villarroel P, Olivares S, Trufello I, Vio F, Andrade M. Diet and lipoproteins in obese women of high and low socio-economic status. Rev. Med. Chile 1989; 117: 3-9.

30 Milos C, Casanueva V, Campos R, Cid X, Silva V, Rodríguez W, Rodríguez MS. Cardiovascular disease risk factors in school children at Concepcion, Chile: Part one: serum lipids in 552 children and adolescents between 6 and 15 years old. Rev. Chil. Pediatr. 1990; 61: 67-73.

31 Casanueva V, Cid X, Chiang MT, Roman R, Milos C, Reyes M, Venegas H, Casanueva P. Serum lipid levels in children and teenagers from Concepción, Chile. Rev. Med. Chile 1996; 124: $1453-61$.

32 World Health Organization (WHO). Obesity. Preventing and Managing the Global Epidemic. Report of a WHO Consultation on Obesity. Geneva: WHO, 1997; 3-5.

33 Kleinman JC, Donahue RP, Harris MI, Finucane FF, Madans $\mathrm{JH}$, Brock DB. Mortality among diabetics in a national sample. Am. J. Epidemiol. 1988; 128: 389-401.

34 Mella I, García de los Ríos M, Parker M, Covarrubia A. Prevalence of diabetes mellitus in the metropolitan area of Santiago. Rev. Med. Chile 1981; 109: 869-75.

35 Larenas G, Arias G, Espinoza O, Charles M, Landaeta O, Villanueva S, Espinoza A. Prevalence of diabetes mellitus in an indigenous (Mapuche) community of the IX Region in Chile. Rev. Med. Chile 1985; 113: 1121-5.

36 Perez-Bravo F, Carrasco E, Santos JL, Calvillan M, Larenas G, Albala C. Type-2 diabetes and obesity prevalence rates in rural Mapuche population from Chile. Nutrition 2001; 17: $236-8$.

37 Uauy R, Albala C, Kain J. Obesity trends in Latin America: transiting from under to overweight. J. Nutr. 2001; 131: 893S-9S.

38 Vega J, Jadue L, Escobar MC, Jalil J, Espejo F, Delgado I, Garrido C, Lastra P, Peruga A. Prevalence of hypertension in Valparaiso. Results of the base survey of CARMEN project. Rev. Med. Chile 1999; 127: 729-38.

39 Fasce E, Perez H, Boggiano G, Lecannelier E. Hypertension in a Chilean urban community. Rev. Chilena de Cardiología 1992; 11: 1-12.

40 Fasce E, Perez H, Boggiano G, Ibáñez P, Nieto C. Hypertension in rural communities of the VIII Region in Chile. Rev. Med. Chile 1993; 121: 1058-67.

41 Rodríguez H, Dockendorf I. High blood pressure in a rural community in Chile. Bol. Of. Sanit. Panam. 1979; 87: $377-88$.

42 Castillo O, Rozovsky J. Fat consumption trend. Rev. Chil. Nutr. 2000; 27S: 105S-12S

43 National Board for Health Promotion (VIDA CHILE). Strategic Plan for Health Promotion 2001-2006. Goals for 2006. Santiago: VIDA CHILE, 2000. 